Tohoku J. exp. Med., 1966, 89, 103-112

\title{
Estimation of Kinin in Peripheral Blood in Man
}

\author{
Keishi Abe, Naoya Watanabe, Naofumi Kumagai, \\ Toraichi Mouri, Toshikatsu Seki and Kaoru Yoshinaga \\ Department of Internal Medicine (Prof. T. Torikai), \\ Tohoku University School of Medicine, Sendai
}

\begin{abstract}
A simple and accurate method for the determination of kinin in blood was described. It consists of the extraction of kinin with $n$-butanol at pH 2.0 , elimination of sodium chloride from butanol phase, re-extraction of kinin into distilled water, concentration under reduced pressure, neutralization and assay on the isolated guinea-pig ileum against synthetic bradykinin as a standard. The recovery of added bradykinin was approximately 50 per cent. The method is also specific to kinin in blood and suitable for the clinical use. The kinin level estimated by this method was about 0-2 $\mathrm{m} \mu \mathrm{g}$ per $\mathrm{ml}$ in normal persons.
\end{abstract}

Seventeen years has elapsed since Rocha e Silva et al. ${ }^{1}$ discovered an active polypetide, bradykinin, which is released by the incubation of pseudoglobulin fraction of plasma protein with trypsin or some snake venom. Until more recently this active substance has only been investigated from physiological or pharmacological standpoint.

Recently, many researchers have given attention to the fact that bradykinin plays important roles as a mediator in reactive hyperemia, ${ }^{2}$ pathogenesis of shock, ${ }^{3}$ allergic diseases, ${ }^{4}$ or the process of inflammation, ${ }^{5}$ and have begun to recognize the participation of this substance in these clinical conditions. In order to evaluate the roles of bradykinin, an assay method of kinin in blood has been studied by several authors. ${ }^{6-8}$ They used almost the same procedure in which kinin was extracted from blood into organic phase. The estimated values, however, were in considerable disagreement among the investigators.

Therefore, it seems to be necessary to develop a more accurate method for the quantitative determination of human blood kinin. The study described in this paper deals with the establishment of a simple and accurate method for the assay of kinin in human blood.

\section{METHODS}

A) Collection of blood samples

A syringe and needle (gauge 19) were siliconized (silicon: Shin-Etsu Chemical

Received for publication, March 7, 1966. 
Industry Co. Ltd., Tokyo, Japan) and kept in a freezer before use. Ten milliliters of venous blood were rapidly drawn from the antecubital vein into the syringe which contained $1 \mathrm{ml}$ of cooled $0.03 \mathrm{M}$ ethylenediaminetetraacetic acid (EDTA) solution. The sample was directly transferred to a centrifuge tube containing half volume of $0.8 \mathrm{~N}$ hydrochloric acid solution and shaken gently for a few minutes for mixing. This step should be carried out as quickly as possible.

\section{B) Extraction}

The mixed solution was adjusted to $\mathrm{pH} 2.0$ (indicator paper $\mathrm{CR}$ ) with $1 \mathrm{~N}$ sodium hydroxide or $1 \mathrm{~N}$ hydrochloric acid and saturated with solid sodium chloride. After the addition of $20 \mathrm{ml}$ of $n$-butanol, the mixture was shaken vigorously for 5 minutes, and centrifuged at 3,000 rpm for 5 minutes. The butanol phase was pipetted to another centrifuge tube.

The extraction was repeated again with $20 \mathrm{ml}$ of butanol. Both extracts were combined, and $10 \mathrm{~g}$ of anhydrous sodium sulfate were added to eliminate water dissolved in butanol phase. This solution was shaken gently for 5 minutes and stored overnight at $-20^{\circ} \mathrm{C}$.

Subsequently, the supernatant was transferred to another tube after centrifugation, and $4 \mathrm{ml}$ of petroleum ether were added. The mixture was reextracted with $4 \mathrm{ml}$ of distilled water under shaking for 5 minutes. The reextraction was repeated with $2 \mathrm{ml}$ of distilled water.

The combined aqueous extract was transferred to a graduated glass tube and concentrated under reduced pressure to a volume around $0.6 \mathrm{ml}$ at below $40^{\circ} \mathrm{C}$. During the concentration, the tube was shaken manually to avoid the burst-out of internal fluid.

Adding one drop of $0.05 \%$ brom thymol blue (BTB), the concentrated extract was neutralized by titrating $0.1 \mathrm{~N}$ sodium hydroxide until the bluish color of BTB appeared, and the neutrality was ascertained by indicator paper MR. Final volume of the extract was adjusted to $2.0 \mathrm{ml}$ with water. This solution was submitted to bioassay. If desired, it was stored at $-20^{\circ} \mathrm{C}$ until the assay.

\section{C) Bioassay}

A guinea-pig (150-250 g), both sexes, was killed by a blow on the head, weighed and bled from the carotid arteries. The terminal ileum was cut out, freed from the mesenterium and washed thoroughly with warm Tyrode solution through the lumen. A 2-3 cm segment of anal side was suspended in a $10 \mathrm{ml}$ bath filled with Tyrode solution containing atropine sulfate $\left(10^{-6}\right)$ and promethazine hydrochloride $\left(10^{-7}\right)$ at $34-36^{\circ} \mathrm{C}$. After 2-3 hours of equilibrium with aeration, standard solution containing $0.05-0.1 \mu \mathrm{g}$ of synthetic bradykinin in $1 \mathrm{ml}$ of Tyrode solution and samples were added to the bath alternatively. The contact time was $1 \mathrm{~min}$, and the interval between each application was $7 \mathrm{~min}$. Contractions of the ileum strip were recorded on a smoked kymograph with a lever. 
The concentration of kinin in the samples was determined by comparing its contractilities with that of standard solution by the four-point method.

\section{COMMENTS ON THE METHODS}

\section{1) Inhibition of the kininase activity}

$E D T A$ : Since the kinin-destroying enzyme, kininase, in blood is so active that the half-life of bradykinin is less than $1 \mathrm{~min}$ in circulating blood, ${ }^{9}$ it is necessary to inhibit the action of kininase in blood in order to estimate the correct blood kinin value. According to Erdös and Wohler, ${ }^{10}$ EDTA was a potent inhibitor to kininase in blood. Therefore, EDTA solution was used to suppress its activity. Fig. 1 illustrates how EDTA prevented the destruction of

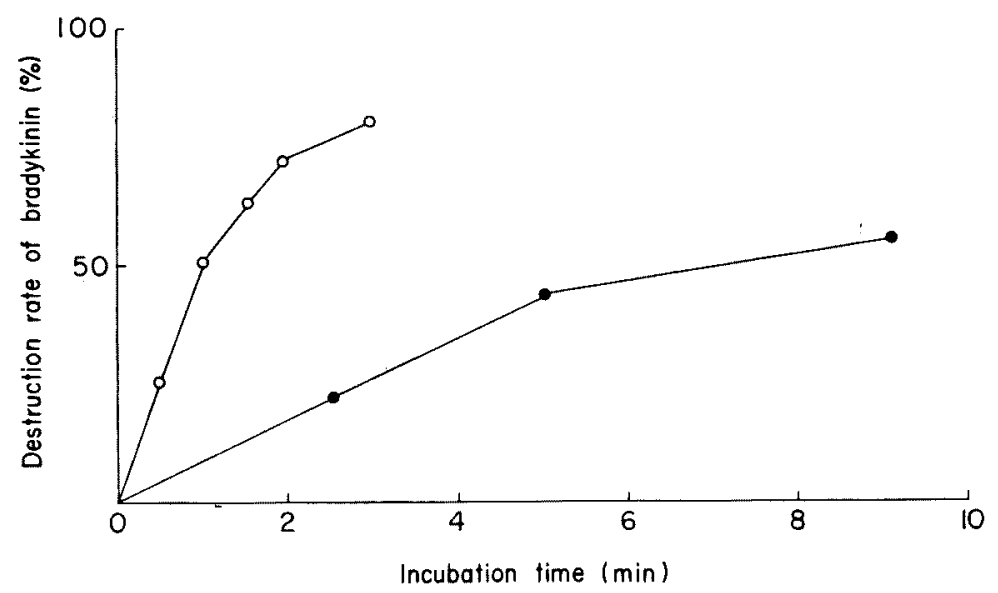

Fig. 1. The relationship of bradykinin destruction and the incubation time.

Open circles: $0.75 \mu \mathrm{g}$ of synthetic bradykinin in $1 \mathrm{ml}$ of Tyrode solution was incubated with $1 \mathrm{ml}$ of venous blood.

Closed circles: The same solution but containing $1 \mathrm{ml}$ of $0.03 \mathrm{M}$ EDTA.

bradykinin in incubated solution. In A solution in which this inhibitor was not contained, 80 per cent of bradykinin was destroyed within 3 min and the half-time was approximately $1 \mathrm{~min}$. On the other hand, the half-time was significantly increased to about $7 \mathrm{~min}$ in B solution containing EDTA.

Cooling: It was previously reported that the kininase activety in blood was greatly influenced by temperature, and the highest activity was observed at $50^{\circ} \mathrm{C}$. As illustrated in Fig. 2, the destruction of bradykinin was reduced progressively as the temperature in the incubation system fell. From this finding, the syringe, the needle and EDTA solution should be kept cold. 


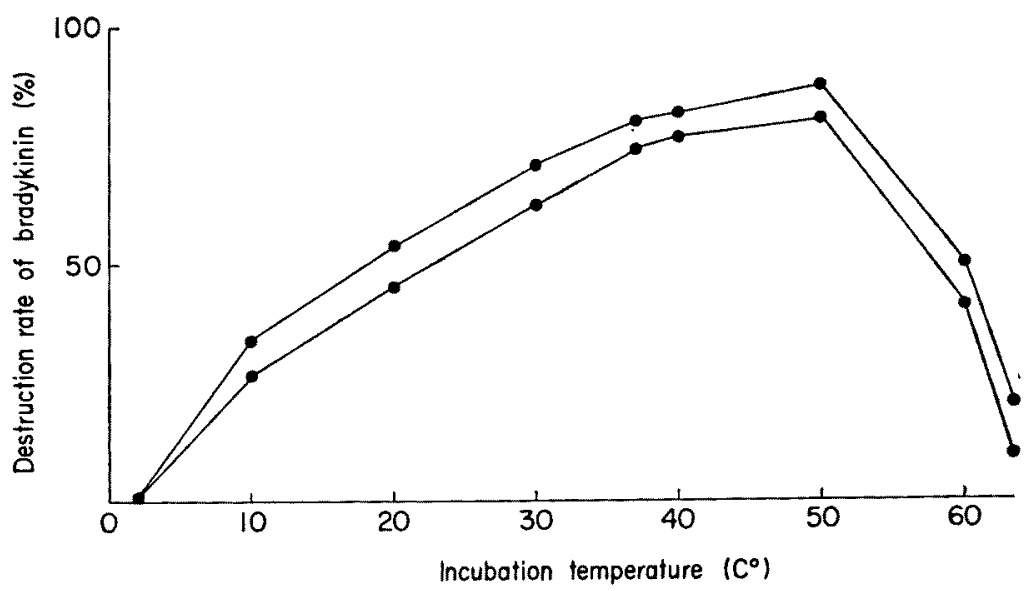

Fig. 2. Effect of temperature on kininase activity in two different tests. $0.75 \mu \mathrm{g}$ of synthetic bradykinin in $1 \mathrm{ml}$ of Tyrode solution was incubated with $1 \mathrm{ml}$ of venous blood for $3 \mathrm{~min}$.

$P H$ : As previously reported," the optimum $\mathrm{pH}$ of kininase in blood was around 7.4. Below this $\mathrm{pH}$, the activity was rapidly reduced and completely inactivated at 5.6 or lower. In the present experiments, mixing with half volume of $0.8 \mathrm{~N}$ hydrochloric acid was applied for complete inactivation of the kininase activity.

\section{2) Prevention of new kinin-formation}

It is generally recognized that a large quantity of inactive kinin-forming enzyme is contained in human plasma. ${ }^{2}$ According to Armstrong and co-workers, ${ }^{12}$ this enzyme is activated by its contact with glass surfaces, and this activation is responsible for plasma kinin release. Therefore, if an unsiliconized syringe was used in blood sampling, the kinin-forming enzyme would be activated by its contact with glass and liberate new kinin, and consequently, the level of kinin would be apparently high.

Actually, the estimated value was higher when blood samples were collected by syringe without siliconization than when the sampling was performed in the standard fashion. From this result, the syringe and the needle should be completely siliconized to estimate a correct kinin content of blood.

\section{3) Extraction}

In the early stage of this study, ethanol was used for the kinin extraction. When blood was drawn by siliconized syringe containing 2 volumes of $96 \%$ ethanol, the clots of blood were formed rapidly in the mixture. These clots sticked fast to the surface of the vessel and was difficult to break or to transfer into a centrifuge tube. In addition, the extracted kinin was partly destroyed during 
the next step of evaporation to dryness after ethanol has completely been flied out in vapor, and a recovery lower than $50 \%$ of added bradykinin was obtained.

After the failure of experiments with ethanol extraction, hydrochloric acid was used to inhibit the action of the kinin-forming and kinin-destroying enzymes. Then blood was treated with an equal volume of $0.2 \mathrm{~N}$ hydrochloric acid according to Horton's method, the recovery rate was as very low as 10 per cent. When blood was treated with an equal volume of ten times concentrated hydrochloric acid, the back-extracted solution was chocolate-colored, and it was difficult to neturalize the solution. On the other hand, the final extracted solution obtained by using a half volume of $0.8 \mathrm{~N}$ hydrochloric acid $(\mathrm{pH}$ in the mixture became around 2.0 ) was colorless, and the recovery rate was constantly higher than 50 per cent.

The most important problem on the extraction procedure was how to lower the concentration of sodium chloride in the final solution which markedly influenced the response of the guinea-pig ileum. This substance in higher concentrations than $0.6 \mathrm{~N}$ had some influence on the response of the guinea-pig ileum as reported previously by us. ${ }^{13}$ Furthermore, in highly sensitive preparations which enabled to assay minute quantities of kinin as in blood, $0.3 \mathrm{~N}$ sodium chloride sometimes elicited slight contractions of the ileum. In an attempt to eliminate sodium chloride, the butanol extract was dehydrated by addition of anhydrous sodium sulfate. If the water in butanol extract was removed, the salt, dissolved in the former, would be also freed from the organic solvent. Table 1 shows the relationship between the amounts of the sodium sulfate added

TABLE 1. The relationship between the amounts of anhydrous sodium sulfate and the concentrations of sodium chloride in the final solution

\begin{tabular}{c|c|c|c}
\hline $\begin{array}{c}\text { No. of } \\
\text { samples }\end{array}$ & $\begin{array}{c}\mathrm{pH} \text { on } \\
\text { extraction }\end{array}$ & $\begin{array}{c}\text { Anhydrous } \\
\text { sodium sulfate (g) }\end{array}$ & $\begin{array}{c}\text { NaCl in the } \\
\text { final solution (Eq) }\end{array}$ \\
\hline 1 & 1.8 & 0 & 0.65 \\
2 & 1.8 & 3 & 0.38 \\
3 & 1.8 & 4 & 0.35 \\
4 & 1.8 & 6 & 0.26 \\
5 & 1.8 & 6 & 0.27 \\
6 & 1.8 & 10 & 0.24 \\
7 & 1.8 & 10 & 0.24 \\
8 & 2.0 & 10 & 0.21 \\
9 & 2.0 & 10 & 0.22 \\
\hline
\end{tabular}

the butanol extract and the concentration of sodium chloride in the final solution. From this result, it is safe to add $10 \mathrm{~g}$ of sodium sulfate for taking off the water.

4) Recovery

The recovery of bradykinin added to blood was examined. After various 
TABLE 2. The recovery rate of bradykinin added to the sample with or without $E D T A$

\begin{tabular}{c|c|l|c}
\hline $\begin{array}{c}\text { No. of } \\
\text { samples }\end{array}$ & $\begin{array}{c}\text { Bradykinin } \\
\text { added }(\mu \mathrm{g})\end{array}$ & EDTA & Recovery rate (\%) \\
\hline 1 & 1.5 & With & 63 \\
& 1.5 & Without & 33 \\
2 & 1.5 & With & 66 \\
& 1.5 & Without & 33 \\
3 & 0.75 & With & 52 \\
& 0.75 & Without & 31 \\
4 & 0.75 & With & 63 \\
& 0.75 & Without & 27
\end{tabular}

to the amounts of bradykinin were added into a siliconized syringe containing EDTA solution, $10 \mathrm{ml}$ of venous blood were drawn into this syringe from the forearm vein. Another sample without the addition of bradykinin was prepared in the same fashion. Kinin in both solutions was simultaneously extracted according to the procedure described above.

As shown in Table 2, a larger proportion of the added bradykinin was lost during the extraction procedure, when EDTA was not used in blood collection, than in the samples treated in the standard fashion. The recovery rates estimated on the present method ranged from 33 to 66 per cent (mean 51.3 \pm 10.5 ) for the added bradykinin concentrations of $0.02-1.5 \mu \mathrm{g}$ (Table 3). Because of 50 per cent recovery, the estimated value was doubled and thus the level of kinin was corrected.

TABLE 3. The overall recovery bradykinin added to the blood through the present method

\begin{tabular}{c|c|c|c|c}
\hline $\begin{array}{c}\text { No. of } \\
\text { samples }\end{array}$ & $\begin{array}{c}\text { Bradykinin } \\
\text { added }(\mu \mathrm{g})\end{array}$ & $\begin{array}{c}\text { Bradykinin } \\
\text { recovered }(\mu \mathrm{g})\end{array}$ & $\begin{array}{c}\text { Blank } \\
\text { activity }(\mu \mathrm{g})\end{array}$ & $\begin{array}{c}\text { Recovery } \\
\text { rate (\%) }\end{array}$ \\
\hline 1 & 0.02 & 0.008 & 0 & 40 \\
2 & 0.04 & 0.017 & 0 & 43 \\
3 & 0.06 & 0.02 & 0 & 33 \\
4 & 0.1 & 0.04 & 0 & 40 \\
5 & 0.25 & 0.13 & 0 & 52 \\
6 & 0.375 & 0.12 & 0 & 48 \\
7 & 0.375 & 0.19 & 0 & 51 \\
8 & 0.375 & 0.24 & 0.02 & 64 \\
9 & 0.75 & 0.39 & 0 & 52 \\
10 & 0.75 & 0.47 & 0 & 63 \\
11 & 1.5 & 1.0 & 0 & 66 \\
12 & 1.5 & 0.95 & 0 & 63 \\
& & & \multicolumn{2}{|c}{ Mean $51.3 \pm 10.5$}
\end{tabular}

\section{5) Specificity}

The active substance obtained by the above method was thermostable 


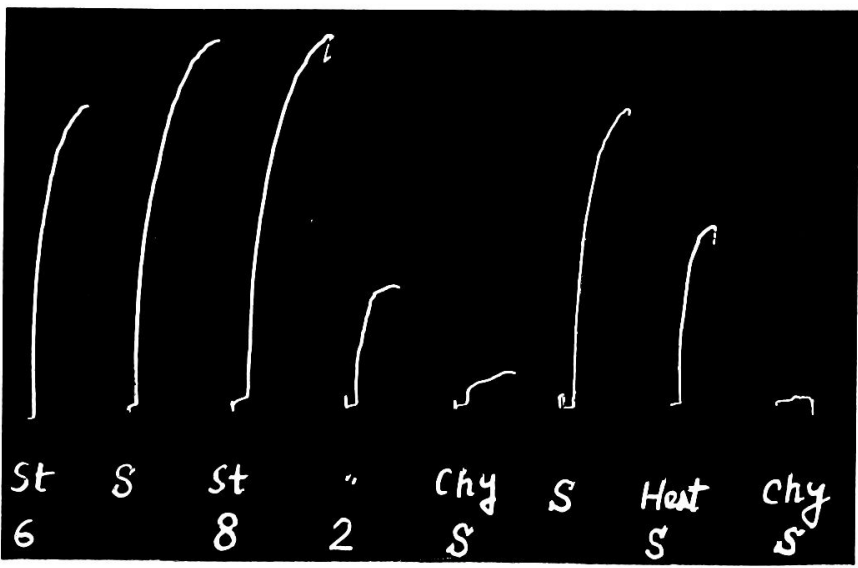

Fig. 3. The contractions of isolated guinea-pig ileum produced by active substance in the extract and by synthetic bradykinin.

St: synthetic bradykinin (unit: $\mathrm{m} \mu \mathrm{g}$ ). $\mathrm{S}$ : the extract $0.5 \mathrm{ml}$. Chy $\mathrm{S}$ : the extract incubated with chymotrypsin 10 units for $30 \mathrm{~min}$ at $37^{\circ} \mathrm{C}$. Heat s: the extract heated for $5 \mathrm{~min}$ at $100^{\circ} \mathrm{C}$.

(Fig. 3), and it elicited a typical slow contraction of the isolated guinea-pig ileum in the same fashion as synthetic bradykinin. Its activity was blocked neither by atropine sulfate $\left(10^{-6}\right)$ nor by promethazine hydrochloride $\left(10^{-7}\right)$.

The action of this substance was also examined on the blood flow in the femoral circulation of dogs. A hind limb of an anesthetized dog was divided at the midthigh level except the femoral artery and the femoral vein. All muscles were completely ligated and cut between the ligatures. The femoral artery and the femoral vein were ligated proximally and cannulated distally with polyethylene tubes, and connected to the femoral artery and jugular vein of another dog. Thus, the cross circulation of the hind limb preparation was performed by the arterial blood of a donor dog under the constant pressure perfusion method using a Sigmamotor pump. The extracted solution was concentrated and injected into the tube connected to the femoral artery, and its effect on the femoral circulation was studied. As illustrated in Fig. 4, the blood flow increased conspicuously with the extract as well as with synthetic bradykinin.

To characterize this substance against proteolytic enzyme, the extracted solution was incubated with chymotrypsin. The active substance was completely destroyed by this enzyme as illustrated in Fig. 3. From these data, the principle in the extract was evidently a polypeptide.

Furthermore, in order to determine whether this polypeptide is identical with kinin or not, the extracted substance was subjected to paper chromatography: The extracted substance was evaporated to dryness and the residue was taken up with a small volume of $80 \%$ ethanol. The alcoholic extract was plotted linearly 


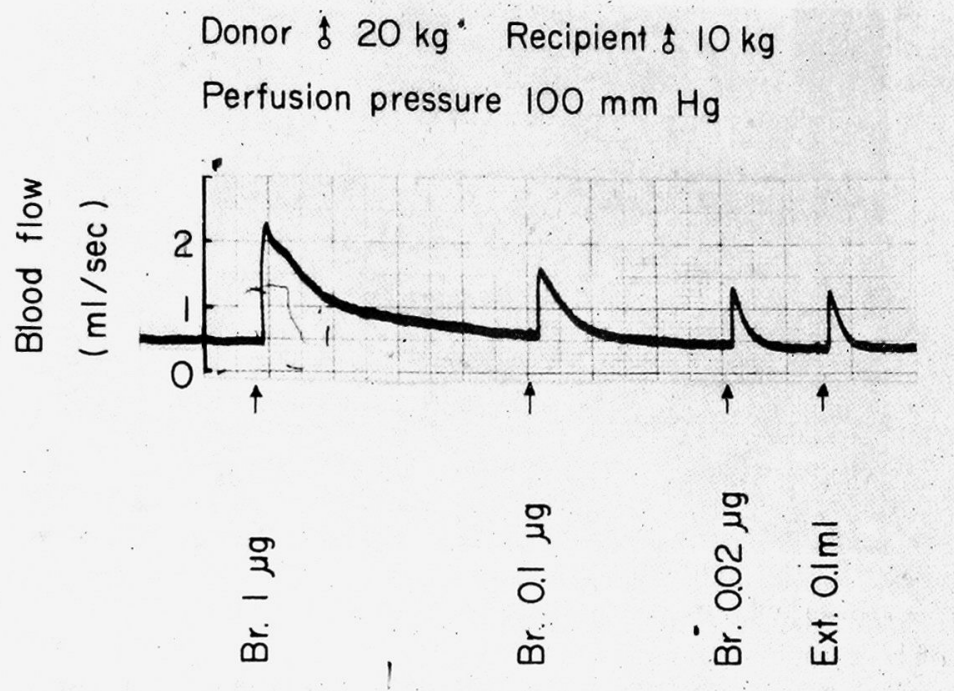

Fig. 4. The comparison of the action of synthetic bradykinin with that of the active substance in the extract on the femoral blood flow of dog's hind limb.

Br.: synthetic bradykinin. Ext.: the extract.

on Toyo Roshi No. 51 paper which corresponds to Whatman No. 1 paper, $5 \times 40$ $\mathrm{cm}$, and developed for 15 hours at around $24^{\circ} \mathrm{C}$ using butanol-acetic acid-water $(4: 1: 1 \mathrm{v} / \mathrm{v})$ as the solvent. After the chromatography, the paper was dried and cut at each $1 \mathrm{~cm}$ distance along the parallel lines to the original one. The active principle was eluted by dipping each fraction of paper in $1 \mathrm{ml}$ of Tyrode and assayed on the guinea-pig ileum. The activity was sharply localized at Rf 0.18 and other active fraction was not observed. When the synthetic kallidin was added to the extracted solution and chromatographed in the same way, the peak at Rf 0.18 was greatly enhanced and other fractions did not cause any response. Thus the polypeptide in the extract could not be distinguished from kinin.

Accordingly, it is obvious that the active principle extracted by the present method is identical with kinin.

6) Blood kinin in healthy subjects

Ten healthy persons were examined by this method as normal controls. The kinin content of blood was $0-2 \mathrm{~m} \mu \mathrm{g}$ per $\mathrm{ml}$. The estimated values of kinin in blood in the various diseases will be published in our forthcoming paper.

\section{DISCUSSION}

Recently, plasma kinin is considered to play improtant roles as a mediator in the various diseases such as angioneurotic edema, ${ }^{14}$ acute pancreatitis, ${ }^{15}$ 
bronchial asthma ${ }^{16}$ or carcinoid syndrome. ${ }^{17}$ To understand the roles of kinin more clearly, an assay method of kinin in blood has been investigated by several researchers. This active polypeptide is very rapidly destroyed by the kinindestroying enzyme, kininase, and readily formed when blood is incubated with the kinin-forming enzyme. Therefore, it is very important to inhibit the actions of both enzymes during the collection of blood and the process of extraction in order to estimate an exact kinin content in blood.

In the method of Binia et al. ${ }^{6}$ or Allwood and Lewis, ${ }^{8}$ ethanol was used for extraction of kinin from blood into the organic phase. However, the estimated values of kinin in blood were greatly different between the two groups of investigators: $1.5 \mathrm{~m} \mu \mathrm{g}$ per $\mathrm{ml}$ by the former against $4-72 \mathrm{~m} \mu \mathrm{g}$ (mean $32 \mathrm{~m} \mu \mathrm{g}$ ) by the latter. We found that kinin was partly destroyed during the course of drying, and the recovery rate was found to be constantly lower than 50 per cent with the alcoholic extraction method.

We also observed that the activation of the kinin-forming enzyme due to the contact of blood with glass surfaces was inhibited by siliconization of glass wares, and the action of kininase in blood was stopped by EDTA, cooling and hydrochloric acid. To extract kinin into the organic phase, $n$-butanol was used in the same way as for the extraction of urinary kinin. When blood was treated with an equal volume of $0.2 \mathrm{~N}$ hydrochloric acid according to Horton's method, the recovery rate was very low. On the other hand, kinin was sufficiently recovered by using a half volume of $0.8 \mathrm{~N}$ hydrochloric acid, but the final extract contained approximately $0.6 \mathrm{~N}$ sodium chloride. Since the salt in such concentrations interfered with the bioassay, it was removed with water from butanol extract by a dehydrating agent, anhydrous sodium sulfate.

The active principle extracted by the present method was thermostable and completely destroyed by the incubation with chymotrypsin, and its activity was blocked neither by atropine sulfate $\left(10^{-6}\right)$ nor by promethazine hydrochloride $\left(10^{-7}\right)$. Therefore, it was obvious that this substance is a polypeptide. Furthermore, this polypeptide elicited a slow contraction of the guinea-pig ileum, produced an increase of blood flow in the femoral circulation of the dog in the same fashion as synthetic bradykinin and showed no different characteristics from synthetic kallidin on paper chromatography.

From these data, the conclusion seems warranted that the polypeptide estimated by the present method is identical with kinin.

The concentrations of kinin in blood of ten healthy persons ranged from 0 to $2 \mathrm{~m} \mu \mathrm{g}$ per $\mathrm{ml}$.

\section{Acknowledgment}

The authors are grateful to Prof. T. Torikai for his leadership and Dr. T. Miura, Department of Pharmacology, for his technical assistance in the experiment on the femoral 
circulation of the dog hind limb. The authors are also indebted to Sandoz Pharmaceutical Co. for the supply of synthetic bradykinin.

\section{References}

1) Rocha e Silva, M., Beraldo, W.T. \& Rosenfeldo, G. Bradykinin, a hypotensive and smooth muscle stimulating factor released from plasma globulin by snake venoms and trypsin. Amer. J. Physiol., 1949, 156, 261-273.

2) Frey, E.K., Kraut, H. \& Werle, E. Kallikrein (Padutin), Ferdinand Enke Verlag, Stuttgart, 1950.

3) Brocklehurst, W.E. The release of histamine and formation of a slow reacting substance during anaphylatic shock. J. Physiol. (Lond.), 1960, 151, 416-435.

4) Brocklehurst, W.E. \& Lahiri, S.C. The production of bradykinin in anaphylaxis. J. Physiol. (Lond.), 1962, 160, 15-16P.

5) Lewis, G.P. Plasma kinins and other vasoactive compounds in acute inflammation. Ann. N.Y. Acad. Sci., 1964, 116, 847-854.

6) Binia, A., Fasciolo, J.C. \& Carretero, C.A. A method for the estimation of bradykinin in blood. Acta physiol. lat-amer., 1963, 13, 101-109.

7) Horton, E.W. An increase in butanol-extractable 5-hydroxytryptamine in venous blood during reactive hyperemia. J. Physiol. (Lond.), 1964, 170, 101-109.

8) Allwood, M.J. \& Lewis, G.P. Bradykinin and forearm blood flow. J. Physiol. (Lond.), $1964,170,571-581$.

9) Saameli, K. \& Eskes, T.K.A.B. Bradykinin and cardiovascular system; estimation of half-life. Amer. J. Physiol., 1962, 203, 261-265.

10) Erdös, E.G. \& Wohler, J.R. Inhibition in vivo of the enzymatic inactivation of bradykinin and kallidin. Biochem. Pharmacol., 1963, 12, 1193-1199.

11) Abe, K., Watanabe, N., Kumagai, N., Miwa, I., Mouri, T., Seki, T., Oikawa, A. \& Yoshinaga, K. Assay of kininase activity in human blood. Tohoku J. exp. Med., $1965,86,77-83$.

12) Armstrong, D., Jepson, J.B., Keele, C.A. \& Stewart, G.T. Pain-producing substance in human inflammatory exsudates and plasma. J. Physiol. (Lond.), 1957, $135,350-370$.

13) Yoshinaga, K., Abe, K., Miwa, I., Aida, M., Maebashi, M. \& Wada, Y. Assay of urinary kinin. Tohoku J, exp. Med., 1963, 81, 246-253.

14) Landerman, N.S., Webster, M.E., Becker, E.L. \& Ratcliffe, H. E. Hereditary angioneurotic edema. J. Allergy, 1962, 33, 330-341.

15) Thal, A.P., Kobold, E.E. \& Hollenberg, M.J. The release of vasoactive substance in acute pancreatitis. Amer. J. Surg., 1963, 105, 708-713.

16) Collier, H.O.J. The action and antagonism of kinins on bronchioles. Ann. N.Y. Acad. Sci., 1963, 104, 290-298.

17) Oates, J.A., MeImon, K., Sjoerdsma, A., Gillespie, L. \& Mason, D.T. Release of a kinin peptide in the carcinoid syndrome. Lancet, 1964, 1, 514-516. 